\title{
Depression and anxiety predict health-related quality of life in chronic obstructive pulmonary disease: systematic review and meta-analysis
}

This article was published in the following Dove Press journal:

International Journal of COPD

20 May 2014

Number of times this article has been viewed

\begin{abstract}
Amy Blakemore ${ }^{1,2}$
Chris Dickens ${ }^{3}$

Else Guthrie ${ }^{2}$

Peter Bower'

Evangelos Kontopantelis'

Cara Afzal ${ }^{2}$

Peter A Coventry ${ }^{4}$

'National Institute for Health Research School for Primary Care Research, Centre for Primary Care, Manchester Academic Health Science Centre, University of Manchester, ${ }^{2}$ Department of Psychiatry,

Manchester Mental Health and Social Care Trust, Manchester Royal Infirmary, Manchester, UK; ${ }^{3}$ Institute of Health Service Research, University of Exeter Medical School and Peninsula Collaboration for Leadership in Health Research and Care, University of Exeter, Exeter, UK; ${ }^{4}$ Collaboration for Leadership in Applied Health Research and Care for Greater Manchester and Manchester Academic Health Science Centre, University of Manchester, Manchester, UK
\end{abstract}

Background: The causal association between depression, anxiety, and health-related quality of life (HRQoL) in chronic obstructive pulmonary disease (COPD) is unclear. We therefore conducted a systematic review of prospective cohort studies that measured depression, anxiety, and HRQoL in COPD.

Methods: Electronic databases (Medline, Embase, Cumulative Index to Nursing and Allied Health Literature [CINAHL], British Nursing Index and Archive, PsycINFO and Cochrane database) were searched from inception to June 18, 2013. Studies were eligible for inclusion if they: used a nonexperimental prospective cohort design; included patients with a diagnosis of COPD confirmed by spirometry; and used validated measures of depression, anxiety, and HRQoL. Data were extracted and pooled using random effects models.

Results: Six studies were included in the systematic review; of these, three were included in the meta-analysis for depression and two were included for the meta-analysis for anxiety. Depression was significantly correlated with HRQoL at 1 -year follow-up (pooled $r=0.48,95 \%$ confidence interval $0.37-0.57, P<0.001)$. Anxiety was also significantly correlated with HRQoL at 1-year follow-up (pooled $r=0.36,95 \%$ confidence interval $0.23-0.48, P<0.001$ ).

Conclusion: Anxiety and depression predict HRQoL in COPD. However, this longitudinal analysis does not show cause and effect relationships between depression and anxiety and future HRQoL. Future studies should identify psychological predictors of poor HRQoL in well designed prospective cohorts with a view to isolating the mediating role played by anxiety disorder and depression.

Keywords: long-term conditions, COPD, quality of life, panic

\section{Background}

Chronic obstructive pulmonary disease (COPD) is responsible for approximately $5 \%$ of deaths worldwide and is predicted to become the third leading cause of death by $2030 .{ }^{1}$ It is a chronic respiratory disease that typically results in a wide range of extrapulmonary comorbidities, such as cardiovascular disease, skeletal muscle dysfunction, osteoporosis, diabetes, anemia, and depression. ${ }^{2,3}$ COPD severity has traditionally been assessed using measures of airflow obstruction, such as forced expiratory volume in one second $\left(\mathrm{FEV}_{1}\right)$. However, the therapeutic focus in COPD has started to shift away from an emphasis on lung function and mortality to management of comorbidities and more patient-centered outcomes related to functioning and health status. This trend is reflected in the increased use and reliance on patient-centered outcomes such as health-related quality of life (HRQoL) to assess the impact of therapeutic strategies in COPD. ${ }^{4}$
Correspondence: Amy Blakemore Rawnsley Building, Manchester Royal Infirmary, Oxford Road, Manchester MI3 9WL, UK

Tel +44 I6I 276533 I

Fax +44 I6I 2732135

Email amy.blakemore@manchester.ac.uk 
HRQoL is a multidimensional concept that refers to quality of life that is directly related to health or illness. It often includes domains related to the physical, social, and psychological impact of illness. ${ }^{5}$ HRQoL is concerned with a patient's experience of illness and can be defined as the subjective perception of the impact of health status on satisfaction with daily life. ${ }^{5-7}$ COPD severity is associated with impaired HRQoL, ${ }^{8-10}$ but poor HRQoL can also exacerbate symptoms of COPD (such as breathlessness) and can have a significant impact on physical functioning, the probability of hospital admission, and mortality. ${ }^{11-18}$

There are a range of psychological factors that might explain variation in respiratory-specific HRQoL over and above markers of disease severity, such as $\mathrm{FEV}_{1}$. Depression and anxiety have both been found to be important predictors of HRQoL in cross-sectional studies, ${ }^{19-24}$ with anxiety explaining over $40 \%$ of the variance in HRQoL in some cases. ${ }^{20}$ Tsiligianni et al conducted a meta-analysis of crosssectional studies and reported that depression and anxiety were highly correlated with respiratory-specific HRQoL; a higher correlation was only found between dyspnea and HRQoL. ${ }^{25}$ Further studies conducted since this review have confirmed this finding, ${ }^{26}$ with one population-based study in Singapore showing that the impact of depression on HRQoL in COPD was significantly greater than in people without COPD. ${ }^{27}$ Some cross-sectional studies have also examined the association between psychological health and more generic measures of HRQoL, such as the Medical Outcomes Study Short Form. ${ }^{28}$ However, even when HRQoL is measured using these generic measures, depression and anxiety still account for a significant proportion of the variance in people with COPD. ${ }^{29,30}$

Findings to date are thus mainly derived from cross-sectional studies, and although results suggest that there is a significant association between depression, anxiety, and HRQoL in COPD, they are not able to determine causal associations between these factors. It is important to consider the temporal and causal association between depression and/or anxiety and HRQoL in order to inform the development of future interventions aimed at improving HRQoL. We have therefore conducted a systematic review with meta-analysis of longitudinal prospective studies to assess the ability of depression and anxiety to predict future HRQoL in patients with COPD.

\section{Methods}

The methods and results for this review are reported in line with the PRISMA (Preferred Reporting Items for Systematic Reviews and Meta-Analyses) guidelines. ${ }^{31}$

\section{Information sources and search strategy}

Studies were identified for inclusion in this review by searching the following electronic databases from inception to June 18, 2013: Medline, Embase, Cumulative Index to Nursing and Allied Health Literature (CINAHL), British Nursing Index and Archive, PsycINFO, and Cochrane database. The search strategy was designed using Medical Subject Headings (MeSH) terms and key words relating to COPD, depression, anxiety, panic, HRQoL, and longitudinal cohort studies for each database. Electronic searches were supplemented by hand searches of reference lists of included papers and relevant reviews.

\section{Eligibility criteria}

Studies were eligible for inclusion in this review if they:

- used a nonexperimental prospective cohort design

- did not include any standardized experimental intervention; this was to ensure that samples included in the review had not been exposed to any intervention which may have modified the association between depression, anxiety, and HRQoL over the duration of the study

- included patients with a diagnosis of COPD confirmed by spirometry as an $\mathrm{FEV}_{1}$ /forced vital capacity ratio $<0.70$ or $\mathrm{FEV}_{1}<80 \%$ of the predicted values according to GOLD (Global initiative for chronic Obstructive Lung Disease) criteria; ${ }^{32}$ studies that included a cohort of patients with a range of chronic physical health problems including COPD were eligible only where data for COPD confirmed by spirometry were reported separately

- used validated self-report measures of either general or respiratory-specific HRQoL

- used validated diagnostic clinical interviews or self-report measures of depression and anxiety; clinical and subthreshold symptoms of depression and anxiety were included.

Studies where depression and anxiety were measured using a subscale of a quality of life measure were excluded. Studies were not excluded by date of publication, sample size, or follow-up period. However, studies that were unpublished, published in abstract form only, or were not published in the English language were not included in this review.

\section{Study selection}

Titles and abstracts were screened (by AB) and full papers of potentially relevant abstracts were retrieved. Full text versions of abstracts were independently screened and final decisions about eligibility were made at a consensus meeting with all review authors. Further information was requested from authors of seven papers, of whom five responded to provide additional information on their papers. 


\section{Data extraction}

An electronic form was developed in Microsoft Excel for the purpose of data extraction. Data were extracted independently by two researchers $(\mathrm{AB}, \mathrm{CA})$ who each looked at all studies. Data were extracted on study design, method and place of recruitment, sample age, sex, smoking history, method of COPD diagnosis, and severity classification $\left(\mathrm{FEV}_{1}\right)$. Scores for HRQoL depression and anxiety were extracted at both baseline and follow-up. Any disagreements between researchers were resolved by discussion.

The main aim of this review was to assess the strength of the longitudinal association between anxiety, depression, and HRQoL in COPD. Where these data were not available in the published papers, authors were contacted by email or letter to request the appropriate data. Where the length of follow-up varied, data were extracted and included in the meta-analysis for the time point closest to 12 months after the baseline measures were taken.

\section{Quality assessment}

Studies were rated for their quality by two researchers ( $\mathrm{AB}, \mathrm{CA})$ using criteria adapted from guidance on the assessment of observational studies ${ }^{33}$ and the Quality Assessment Tool for Quantitative Studies. ${ }^{34}$ Any disagreements were resolved by discussion.

The quality review included assessment of selection bias, response bias, the reliability and validity of data collection methods, withdrawals and dropouts, and whether confounding variables were adequately controlled for. Three key criteria were deemed as essential to the quality review and each study was awarded one point for each criterion met; this was then used as a framework for narrative synthesis of the results. These key criteria were: response rate of $70 \%$ or greater at baseline; control for confounding factors in analysis; and response rate greater than $70 \%$ at follow-up. ${ }^{34}$

\section{Data analysis and synthesis}

Data analysis was conducted in Stata (version 12.1; StataCorp LP, College Station, TX, USA) and Comprehensive Meta-analysis (version 2.2.064; BioStat International, Inc., Tampa, FL, USA). Where possible, indices of association between depression or anxiety and total scores for HRQoL measures were included in the meta-analysis. However, where total scores were not available, the most appropriate subscale score was used. For the St George's Respiratory Questionnaire (SGRQ) ${ }^{35}$ the Impact subscale was used because it provides a measure of social functioning and psychological disturbance associated with respiratory disease. ${ }^{35}$ We aimed to extract regression coefficients where possible. However, since regression coefficients were not available in any of the studies, correlation coefficients were extracted and transformed for meta-analysis using Fisher's $Z$ transformation in order to normalize the distribution of $r$, making the variance independent of the unknown true value of the correlation. ${ }^{36}$ The $Z$ scores were then pooled across the studies using a random effects model to account for variation between studies. The pooled effect size was then converted back to a correlation coefficient. ${ }^{37} \mathrm{~A}$ pooled correlation coefficient of $r=0.10$ was considered small, $r=0.25$ as moderate, and $r=0.40$ as large.$^{38}$ Where papers did not report either a correlation coefficient or the data required to compute a correlation coefficient, we contacted the corresponding author and requested the missing data. Two authors responded and supplied the relevant data. ${ }^{39,40}$ Statistical heterogeneity was investigated using $I^{2}$ which measures the percentage of the variation across studies that is due to heterogeneity and cannot be explained by chance..$^{41}$ Low heterogeneity is indicated by an $I^{2}$ result of $\leq 25 \%$, moderate heterogeneity by around $50 \%$, and high heterogeneity is $\geq 75 \%{ }^{41}$

\section{Results}

Electronic and hand searches identified 380 citations excluding duplicates. Of these, 236 citations were excluded on the basis that their abstracts did not meet the eligibility criteria for this review. The full texts for 144 citations were reviewed. Six studies were identified that met the criteria for inclusion in the systematic review, ${ }^{39,40,42-45}$ of which three were eligible for inclusion in meta-analysis for depression ${ }^{39,40,43}$ and two for anxiety. ${ }^{39,40}$ The flow of the studies and reasons for exclusion are presented in the PRISMA flow chart in Figure 1. ${ }^{31}$

\section{Characteristics of studies and populations}

The characteristics of each study are summarized in Table 1 . In total, there were data for 895 COPD patients, of whom $69.8 \%(n=625)$ were male. Five of the studies included both male and female COPD patients and one was limited to male patients. ${ }^{39}$ The mean age across the studies ranged from 64.6 years ${ }^{44}$ to 73.5 years. ${ }^{42}$ Length of follow-up ranged from 3 months $^{40}$ to 5 years. ${ }^{39}$

The majority of participants $(61.1 \%, \mathrm{n}=547)$ were recruited in hospital following admission for acute exacerbations of COPD. ${ }^{42,43}$ The remaining $38.9 \%(n=348)$ were recruited from hospital outpatient settings. One study excluded patients who had experienced an acute exacerbation in the previous 6 weeks, ${ }^{39}$ and another reported that none of the patients in their sample had been admitted for an acute 


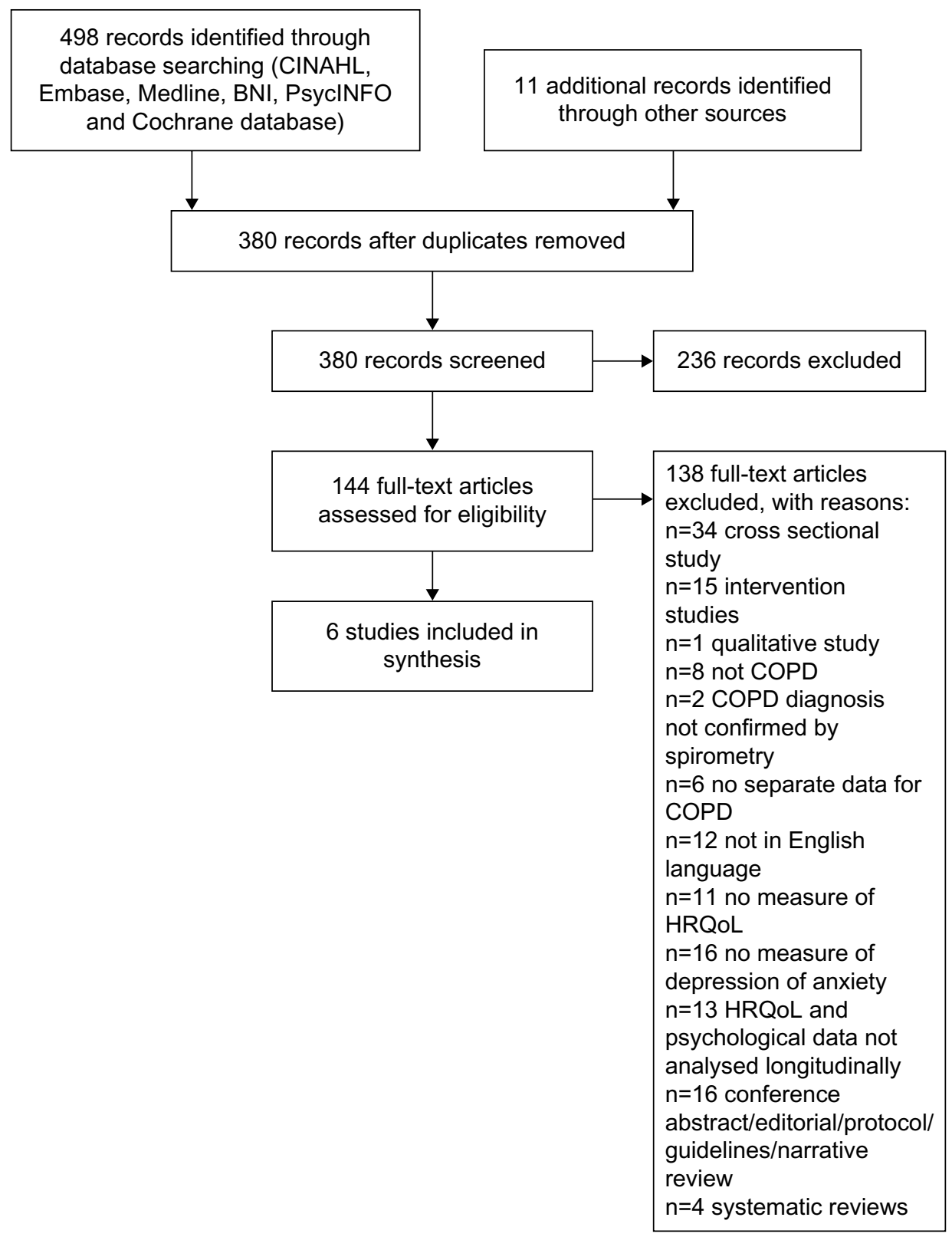

Figure I Search flowchart.

Abbreviations: BNI, British Nursing Index and Archive; CINAHL, Cumulative Index to Nursing and Allied Health Literature; COPD, chronic obstructive pulmonary disease; HRQoL, health-related quality of life.

exacerbation at the time they participated in the study. ${ }^{44}$ All included studies recruited patients with a mean predicted $\mathrm{FEV}_{1}<50 \%$, which indicates severe COPD. ${ }^{32}$

Four of the six studies ${ }^{39,40,42,43}$ measured HRQoL using COPD-specific measures, including the SGRQ and the Chronic Respiratory Questionnaire. ${ }^{46}$ One study ${ }^{45}$ used the Sickness Impact Profile,${ }^{47}$ and another used both the Sickness Impact Profile and the SGRQ. ${ }^{44}$ Four of the six studies ${ }^{39,40,42,44}$ measured symptoms of depression using the Hospital Anxiety and Depression Scale (HADS). ${ }^{48}$ One study ${ }^{43}$ used the Hopkins Symptom Checklist, ${ }^{49}$ and one study used the Profile of Mood States. ${ }^{50}$ Three studies measured anxiety symptoms using the HADS..$^{39,40,44}$ No study measured panic disorder or any other specific anxiety disorders.

The prevalence of anxiety and depression varied at baseline (Table 1). The three studies that recruited patients following an admission to hospital reported that patients in their sample were experiencing symptoms of depression at baseline. ${ }^{40,42,43}$ One study reported that $44.4 \%$ of their sample had symptoms of depression at baseline, but did not report mean HADS scores. ${ }^{42}$ Three of the studies that recruited hospital outpatients reported that their sample had symptoms of depression that were not clinically significant at baseline. ${ }^{39,44,45}$ However, one study of outpatients reported 


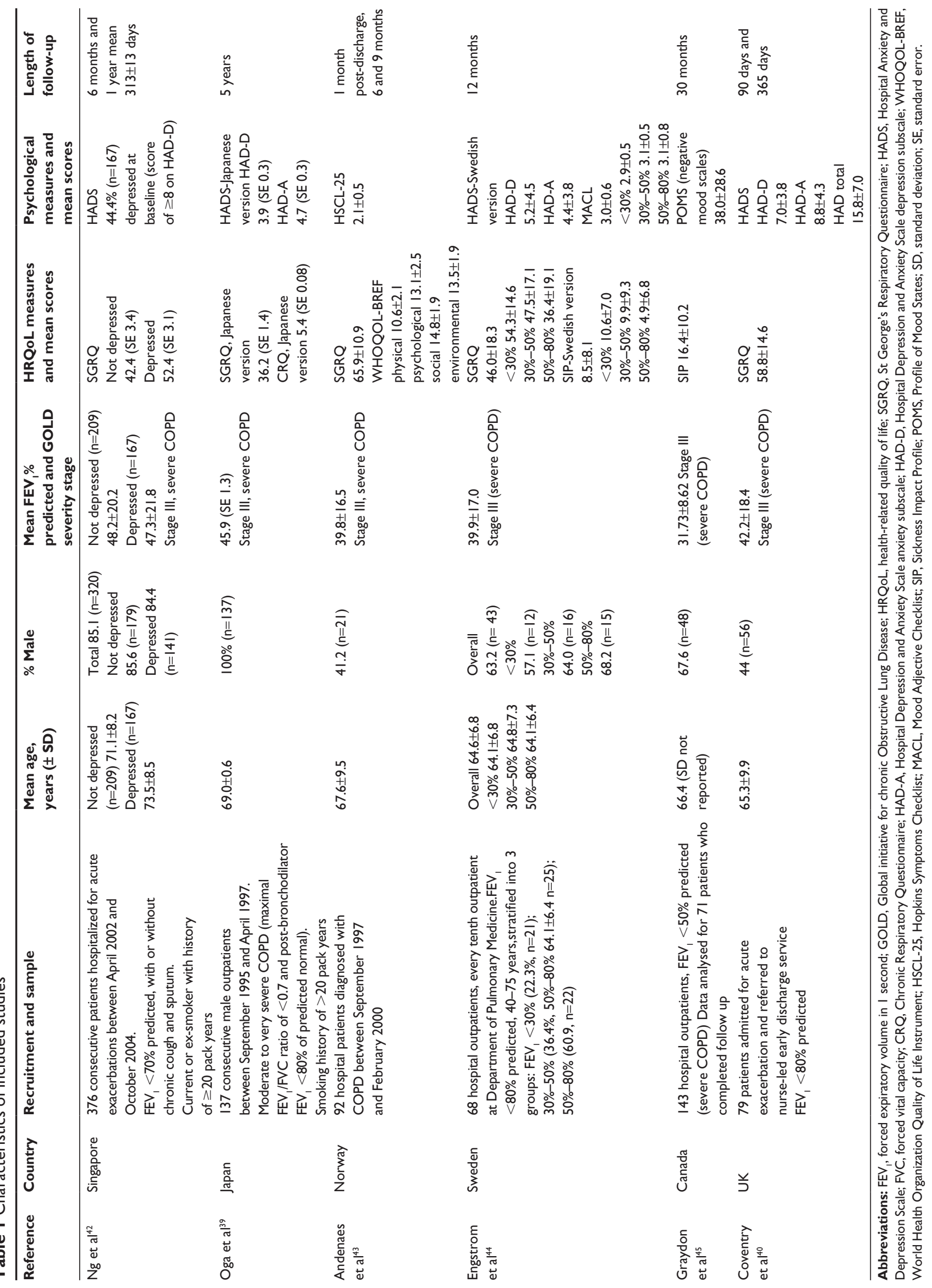


a significant increase in depressive symptoms in their sample over a 5 -year study period. ${ }^{39}$

Three studies measured anxiety using the HADS; two were studies of hospital outpatients and neither reported clinical levels of anxiety at baseline; ${ }^{39,44}$ one was a study of patients admitted to hospital and discharged to a nurse-led early discharge service and reported a mean HADS anxiety score of 8.8 , indicating mild anxiety symptoms. ${ }^{40,48}$

\section{Quality of included studies}

The results of the quality review are presented in Table 2 . The quality of the studies varied greatly. One study met the requirements for all three of the quality criteria, ${ }^{42}$ two studies met two of the criteria, ${ }^{40,43}$ and three studies did not meet any ${ }^{39,44,45}$ Five out of the six studies studies ${ }^{39,40,42,43,45}$ reported attrition rates at follow-up, two of which found that those who completed the study were more likely to be younger than those who did not. ${ }^{43,45}$ Furthermore, in one study, ${ }^{39}$ over $40 \%$ of patients who did not complete follow-up at 5 years had died. In this study, patients who had died were found to be significantly older, more breathless, and had worse HRQoL than those who did complete follow-up.

\section{Longitudinal association of depression with HRQoL in COPD}

Six longitudinal cohort studies investigated the association between depression and HRQoL in COPD (Table 1), but only three studies could be included in the meta-analysis for depression. ${ }^{39,40,43}$

$\mathrm{Ng}$ et $\mathrm{al}^{42}$ scored the highest score of 3 in the quality review and reported that depressed patients had significantly worse HRQoL at baseline across all subscales of the SGRQ, and this was maintained at 12-month follow-up. However, the authors did not analyze the predictive effect of depression on HRQoL across the 12-month period. Two of the studies scored 2 in the quality review. ${ }^{40,43}$ Andenaes et $\mathrm{al}^{43}$ studied patients who were admitted to hospital with COPD and reported a significant correlation between depression at baseline and HRQoL on follow-up at 6 and 9 months. In this study, depression was significantly correlated with the respiratory-specific SGRQ Impact subscale $(r=0.28, \mathrm{n}=51, P<0.05,95 \%$ confidence interval $[\mathrm{CI}]$ not reported) and also the physical domain ( $r=-0.64, \mathrm{n}=51, P<0.01,95 \% \mathrm{CI}$ not reported), psychological domain ( $r=-0.62, \mathrm{n}=51, P<0.01,95 \% \mathrm{CI}$ not reported), and environmental domain $(r=-0.41, \mathrm{n}=51, P<0.01,95 \% \mathrm{CI}$ not reported), but not with the social domain $(r=-0.23$ ) of the WHOQoL-BREF (World Health Organization Quality of Life Instrument). Coventry et $\mathrm{al}^{40}$ found that depression at baseline

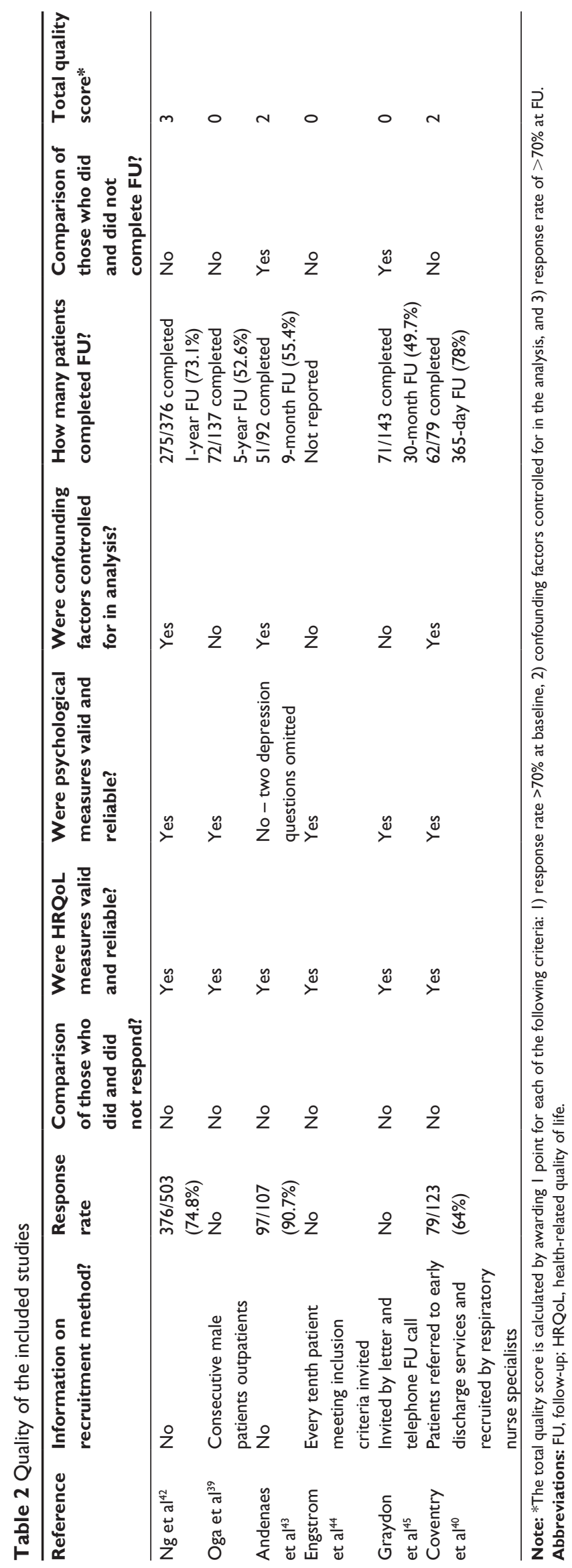


was significantly correlated with respiratory-specific HRQoL at 3 months $(r=0.52, P<0.001)$ and 1-year follow-up $(r=0.64$, $P<0.001)$ in patients discharged from hospital under the care of early discharge services (Table 3 ). Three studies did not meet any of the key quality criteria. ${ }^{39,44,45}$ Firstly, Oga et al ${ }^{39}$ reported that depression measured at baseline was significantly correlated with respiratory-specific HRQoL at 1-year follow-up ( $r=0.47, P<0.001$ ); this association remained after 5 years $(r=0.47, P<0.001)$ in the sample of outpatients with severe COPD. ${ }^{39}$ Secondly, Engstrom et al found that depression as measured by the Hospital Depression and Anxiety Scale depression subscale $(b=0.39, P<0.001), 6$-minute walk distance $(b=0.05, P<0.05)$, and vital capacity $(b=0.15$, $P<0.001)$ were the best predictors of HRQoL, explaining $59 \%$ of the variance in multiple regression analyses when SGRQ scores were excluded. ${ }^{44}$ Finally, Graydon et al found that negative mood, as measured by the Profile of Mood States at baseline, was significantly correlated with HRQoL after 12 months ( $r=0.49, P<0.0001,95 \%$ CI not reported). ${ }^{45}$ However, they did not include depression as a predictor variable in their multiple regression analyses.

\section{Meta-analysis of longitudinal association between depression and HRQoL in COPD}

Three studies were eligible for inclusion in meta-analysis for depression. ${ }^{39,40,43}$ Random effects meta-analysis of the three studies (Figure 2) found a large positive correlation between depression at baseline and HRQoL measured at follow-up ( $r=0.48,95 \%$ CI $0.37-0.57, P<0.001)$. A moderate to high degree of heterogeneity was found across the studies $(Q=6.60$ $\left.d f=2, P=0.037, I^{2}=69.7 \%\right) .^{41}$

\section{Longitudinal association of anxiety with HRQoL in COPD}

Two cohort studies report the longitudinal association between anxiety and HRQoL in COPD (Table 4). ${ }^{39,40}$ The study by Coventry et al met two of the key quality criteria for this review and found that anxiety at baseline was significantly correlated with respiratory-specific HRQoL at 3 months $(r=0.40, P=0.002)$ but this did not remain significant at 1 -year follow-up $(r=0.26, P=0.052) .{ }^{40}$ The second study did not meet any of the key quality criteria but reported that anxiety was correlated with respiratory-specific HRQoL at 1-year $(r=0.41, P<0.001)$ and 5-year follow-up ( $r=0.51$, $P<0.001) .{ }^{39}$

\section{Meta-analysis of longitudinal association between anxiety and HRQoL in COPD}

Two studies were eligible for inclusion in the meta-analysis. ${ }^{39,40}$ The random effects meta-analysis of the two studies (Figure 3) found that anxiety at baseline was associated with a moderate and significant positive correlation with HRQoL at follow-up ( $r=0.36,95 \%$ CI $0.23-0.48, P<0.001)$. A low degree of heterogeneity was found across the studies $(Q=1.22$, $\left.d f=1, P=0.269, I^{2}=18.3 \%\right)$.

\section{Discussion}

We conducted a systematic review and meta-analysis of longitudinal cohort studies to assess the temporal association between depression and anxiety and HRQoL in COPD. We identified six studies in total, of which three met the criteria for inclusion in the meta-analysis. Results indicated that both depression and anxiety predict future HRQoL. The association was stronger for depression than for anxiety.

Table 3 Longitudinal correlations between depression and HRQoL in chronic obstructive pulmonary disease

\begin{tabular}{|c|c|c|c|c|c|c|}
\hline Reference & $\begin{array}{l}\text { Depression } \\
\text { measure }\end{array}$ & HRQoL measure & $\begin{array}{l}\text { Length of } \\
\text { follow-up }\end{array}$ & $\begin{array}{l}\text { Sample } \\
\text { size }\end{array}$ & $\begin{array}{l}\text { Correlation } \\
(r)\end{array}$ & $P$-value \\
\hline \multirow[t]{7}{*}{ Andenaes et al ${ }^{43}$} & HSCL-25 & SGRQ symptoms & 9 months & 51 & -0.079 & NS \\
\hline & HSCL-25 & SGRQ impact & 9 months & 51 & 0.279 & $<0.05$ \\
\hline & HSCL-25 & SGRQ activities & 9 months & 51 & -0.138 & NS \\
\hline & HSCL-25 & WHOQOL physical & 9 months & 51 & -0.638 & $<0.001$ \\
\hline & HSCL-25 & WHOQOL psychiatric & 9 months & 51 & -0.622 & $<0.001$ \\
\hline & HSCL-25 & WHOQOL social & 9 months & 51 & -0.225 & NS \\
\hline & HSCL-25 & WHOQOL environment & 9 months & 51 & -0.405 & $<0.01$ \\
\hline \multirow[t]{4}{*}{ Oga et $\mathrm{al}^{39}$} & HAD-D & SGRQ total & I year & 128 & $0.47 I$ & $<0.001$ \\
\hline & HAD-D & CRQ total & I year & 128 & -0.581 & $<0.001$ \\
\hline & HAD-D & SGRQ total & 5 years & 72 & 0.473 & $<0.001$ \\
\hline & HAD-D & CRQ total & 5 years & 72 & -0.549 & $<0.001$ \\
\hline \multirow[t]{2}{*}{ Coventry et al ${ }^{40}$} & HAD-D & SGRQ total & 3 months & 79 & 0.517 & $<0.001$ \\
\hline & HAD-D & SGRQ total & I year & 62 & 0.636 & $<0.001$ \\
\hline
\end{tabular}

Abbreviations: HSCL-25, Hopkins Symptoms Checklist; SGRQ, St George's Respiratory Questionnaire; CRQ, Chronic Respiratory Questionnaire; HAD-D, Hospital Anxiety and Depression Scale depression subscale; HRQoL, health-related quality of life; NS, not significant; WHOQOL-BREF, World Health Organization Quality of Life Instrument. 
Table 4 Longitudinal correlations between anxiety and HRQoL in chronic obstructive pulmonary disease

\begin{tabular}{|c|c|c|c|c|c|c|}
\hline Reference & $\begin{array}{l}\text { Anxiety } \\
\text { measure }\end{array}$ & $\begin{array}{l}\text { HRQoL } \\
\text { measure }\end{array}$ & $\begin{array}{l}\text { Length of } \\
\text { follow-up }\end{array}$ & $\begin{array}{l}\text { Sample } \\
\text { size }\end{array}$ & $\begin{array}{l}\text { Correlation } \\
(r)\end{array}$ & $P$-value \\
\hline \multirow[t]{4}{*}{ Oga et $\mathrm{al}^{39}$} & HAD-A & SGRQ total & I year & 128 & 0.412 & $<0.001$ \\
\hline & HAD-A & CRQ total & I year & 128 & -0.534 & $<0.001$ \\
\hline & HAD-A & SGRQ total & 5 years & 72 & 0.505 & $<0.001$ \\
\hline & HAD-A & CRQ total & 5 years & 72 & $-0.64 I$ & $<0.001$ \\
\hline \multirow[t]{2}{*}{ Coventry et $\mathrm{al}^{40}$} & HAD-A & SGRQ total & 3 months & 79 & 0.369 & 0.002 \\
\hline & HAD-A & SGRQ total & I year & 62 & 0.258 & 0.052 \\
\hline
\end{tabular}

Abbreviations: HAD-A, Hospital Anxiety and Depression Scale anxiety subscale; HRQoL, health-related quality of life; SGRQ, St George's Respiratory Questionnaire; CRQ, Chronic Respiratory Questionnaire.

\section{Strengths and limitations}

This review has several strengths. Firstly, the search was designed to take a broad approach to the identification of papers that included depression and anxiety. Terms to identify both clinically significant and subclinical depression and anxiety symptoms were included. Secondly, the search strategy for this review was designed to find cohort studies that had investigated the strength of the longitudinal association between depression, anxiety or panic disorder, and HRQoL in COPD which has not been done before. The decision to exclude studies where samples had been exposed to any intervention was made to ensure that any prospective change in HRQoL would be unconfounded with treatment effects. Furthermore, cohort studies are often easier to recruit into than randomized controlled trials, and therefore the samples may be less open to threats to their external validity. ${ }^{51}$ The search resulted in identification of 380 studies, a relatively small number for a systematic review. Therefore, it is possible that inclusion of methodological terms to locate only prospective studies may have reduced the sensitivity of the search. However, we are confident that our search identified all potentially eligible relevant studies and we believe we have identified at least two studies ${ }^{40,45}$ not included in a recent meta-analysis of studies that measured factors influencing HRQoL in COPD. ${ }^{25}$ Finally, the detection of between-study variance can be interpreted as a positive finding since the very likely present heterogeneity has been identified and appropriately accounted for using a random effects model. ${ }^{52}$

This review has some weaknesses. Firstly, we used a quality scoring system that presents an overall quality score which rates methodological weaknesses equally. There is a lack of empirical support for the assumption that all methodological weaknesses have equal weight. Therefore, we present details of the performance of each study on each methodological criterion and also highlight the three criteria deemed to be most important for longitudinal studies. ${ }^{34}$ The quality review highlighted several methodological issues with the studies eligible for inclusion in this review. One of the studies that was rated as the highest quality ${ }^{42}$ was not eligible for inclusion in the meta-analysis because data on the longitudinal association between baseline depression or anxiety and HRQoL at follow-up were not available. The three studies that did report this data were of varying quality, with two meeting two of the specified quality requirements, ${ }^{40,43}$ and one failing to meet any. ${ }^{39}$ Only one study ${ }^{40}$ provided information on sampling and recruitment procedures and recruitment response rates.

Therefore, it was not possible to evaluate whether the sampling method was open to selection bias in the included studies of lower quality. Furthermore, none of the studies provide any comparison between those who were and those who were not recruited, making evaluation of possible response bias impossible. The inconsistent reporting of response and attrition bias throughout the studies has implications for the



Figure 2 Forest plot of the longitudinal effect of depression on health-related quality of life in COPD.

Notes: Heterogeneity $\chi^{2}=6.60(d f=2) ; P=0.037 ; P^{2}=69.7 \%$.

Abbreviations: $\mathrm{Cl}$, confidence interval; COPD, chronic obstructive pulmonary disease; SGRQ, St George's Respiratory Questionnaire. 


\begin{tabular}{lrrrrrr} 
Study name & Outcome & \multicolumn{5}{c}{ Statistics for each study } \\
\cline { 3 - 7 } & & Correlation & Lower Upper \\
& & 0.412 & 0.257 & 0.546 & 4.897 & 0.000 \\
Oga et al ${ }^{39}$ & SGRQ total & 0.258 & 0.011 & 0.476 & 2.047 & 0.041 \\
Coventry et al $^{40}$ & SGRQ total & 0.364 & 0.233 & 0.482 & 5.191 & 0.000
\end{tabular}



Figure 3 Forest plot of the longitudinal effect of anxiety on health-related quality of life in COPD.

Notes: Heterogeneity $\chi^{2}=1.22(d f=I) ; P=0.269 ; P^{2}=18.3 \%$.

Abbreviations: $\mathrm{Cl}$, confidence interval; COPD, chronic obstructive pulmonary disease; SGRQ, St George's Respiratory Questionnaire; HAD-A, Hospital Anxiety and Depression Scale anxiety subscale.

inferences that can be drawn from this review. It may be that the results cannot be generalized to older COPD patients because they were less likely to complete follow-up in two studies, ${ }^{42,44}$ although these studies were not eligible for inclusion in the meta-analysis. All of the included studies used validated measures of quality of life and psychological factors. However, one study ${ }^{43}$ that used the Hopkins Symptom Checklist (HSCL-25) modified the measure, removing two of the items relating to suicidal ideation and loss of libido, which are symptoms commonly associated with depression. This reduces the validity of the measure and may have resulted in an underestimate of the prevalence of depressive symptoms in this sample. Unpublished studies were not included in this review, which may have introduced publication bias into this review because studies that report higher effect sizes are more likely to be published. ${ }^{53}$ Where total scores for HRQoL measures were not available for meta-analysis, the most appropriate subscale was chosen. In the case of one paper, ${ }^{43}$ the SGRQ impact subscale was chosen because it provides a measure of social functioning and psychological disturbance that would maximize any observed association between depression and HRQoL. We did not formally test for publication bias in this review due to the small number of studies eligible for inclusion. ${ }^{54}$ Finally, one of the assumptions made in random effects meta-analysis is that study effects should be normally distributed. This is not always easy to confirm when the number of studies included in the model is small. However, methods have been found to be relatively robust even under extreme distributional scenarios. ${ }^{55}$

\section{Implications for research and practice}

The results of the meta-analysis show that depression and anxiety predict future HRQoL. These findings are consistent with the results of a recently published systematic review and meta-analysis that assessed the association between psychological and symptom-based factors and HRQoL in COPD patients. ${ }^{25}$ Tsiligianni et al found that depression, anxiety, exercise, and dyspnea were more highly correlated with
HRQoL in COPD than $\mathrm{FEV}_{1}{ }_{1}$, but this finding was based only on cross-sectional studies and therefore did not include several studies which were eligible to be included for metaanalysis in our review. ${ }^{39,40,43}$ Our review, which is the first to only include longitudinal studies, has further advanced our knowledge of the association between depression and anxiety and HRQoL in COPD by showing that depression and anxiety are correlated with prospective HRQoL. Unfortunately, we were not able to compare the association between depression and anxiety and HRQoL with that of $\mathrm{FEV}_{1}$ because the necessary data were not reported in the published papers. Two authors were contacted ${ }^{39,40}$ and invited to provide the correlations between $\mathrm{FEV}_{1}$ and HRQoL. However, only one author responded, so the analysis could not be completed. This should be a priority for future longitudinal research in this area.

Future studies would be improved by including other common mental health problems that are prevalent in COPD. Panic disorder has a prevalence in COPD estimated to be ten times that of the prevalence in the general population. ${ }^{56,57}$ Panic disorder is known to have a significant negative impact on quality of life in the general population ${ }^{58,59}$ and in patients with long-term conditions such as heart failure ${ }^{60}$ and diabetes. ${ }^{61}$ However, no studies were identified in this review that had considered the impact of panic attacks or panic disorder in COPD. Panic attacks and panic disorder comorbid with COPD have been found to cause greater levels of distress relating to physical health, ${ }^{62}$ and to predict worse health outcomes, including increased hospital admissions ${ }^{63}$ and poorer functional status. ${ }^{64}$ Therefore, it is important to investigate if panic disorder is a significant driver of $\mathrm{HRQOL}$ in COPD because it may be a more important predictor than depression or generalized anxiety.

The findings of this review highlight the importance of regularly assessing patient-centered outcomes such as HRQoL in people with COPD, regardless of their disease severity as measured by lung function. HRQoL is an important marker of functioning, and is potentially mediated by extrapulmonary 
features of COPD such as anxiety and depression. Whereas self-management and education have had limited impact on the psychological health of COPD patients, ${ }^{65-67}$ case management that draws on integrated and collaborative approaches has been shown to reduce depression and improve physical health in people with diabetes and coronary heart disease, ${ }^{68}$ although their effectiveness and safety in COPD is unknown. ${ }^{69}$ As well as scope for testing the acceptability and effectiveness of collaborative care models in COPD, there is also a need to test mediational models proposing that psychological processes and improvements in psychological health predict improvements in HRQoL and possibly improve physical health outcomes and responses to rehabilitation. ${ }^{70}$

\section{Conclusion}

The findings of this review confirm that there is an association between depression, anxiety, and HRQoL that endures over time. However, this longitudinal analysis does not show cause and effect between depression and anxiety and future HRQoL. Future studies should identify psychological predictors of poor HRQoL in well designed prospective cohorts with a view to isolating the mediating role played by anxiety disorders and depression.

\section{Acknowledgments}

This study was funded by the National Institute for Health Research under its Programme Grants for Applied Research programme (grant RP-PG-0707-10162), by the University of Manchester (PB, EK, PAC), and the National Institute for Health Research and Care (CLAHRC) for the South West Peninsula (CD). This article presents independent research funded by the National Institute for Health Research (NIHR) under its Programme Grants for Applied Research scheme (RP-PG-070710162). The views expressed are those of the authors and not necessarily those of the NHS, the NIHR or the Department of Health. We wish to acknowledge the contribution of authors who provided additional information on their studies, namely, C Engstrom and T Oga.

\section{Author contributions}

AB: planned and designed this systematic review and meta-analysis, the inclusion and exclusion criteria, and search strategies; conducted the search, identified eligible papers, extracted the data, and performed the meta-analysis; interpreted findings and wrote the drafts of the paper for submission; coordinated with coauthors to collate comments; and wrote the final draft of the paper. CD: supervised the planning and design of this review and meta-analysis; assisted in the development of inclusion and exclusion criteria, development of search strategies, meta-analysis, interpretation of findings, and drafting of the paper; and approved the final version of the paper. EG: supervised the planning and design of this review and meta-analysis; assisted in the development of inclusion and exclusion criteria, development of search strategies, meta-analysis, interpretation of findings, and drafting of the paper; and approved the final version of the paper. PB: supervised the planning and design of this review and meta-analysis; assisted in the development of inclusion and exclusion criteria, development of search strategies, metaanalysis, interpretation of findings, and drafting of the paper; and approved the final version of the paper. EK: supervised the planning and design of this review and meta-analysis; assisted in the development of inclusion and exclusion criteria, development of search strategies, meta-analysis, interpretation of findings, and drafting of the paper; and approved the final version of the paper. CA: Made a substantial contribution to the acquisition and interpretation of data by assisting in data extraction, reviewing the quality of included papers, drafting of the paper, making critical revisions to the final draft and approved the final version of the paper. PAC: supervised the planning and design of this review and meta-analysis, assisted in the development of inclusion and exclusion criteria, development of search strategies, meta-analysis, interpretation of findings, drafting of the paper; and approved the final version of the paper.

\section{Disclosure}

None of the authors had competing interests to declare.

\section{References}

1. World Health Organization. Global surveillance, prevention and control of chronic respiratory disease: a comprehensive approach. Geneva, Switzerland: World Health Organization; 2007. Available from: http://www.who.int/ gard/publications/GARD_Manual/en/. Accessed March 11, 2014.

2. Agusti A, Calverly P, Celli B, et al; Evaluation of COPD Longitudinally to Identify Predictive Surrogate Endpoints (ECLIPSE) investigators. Characterisation of COPD heterogeneity in the ECLIPSE cohort. Respir Res. 2010;11:122.

3. Huertas A, Palange P. COPD: a multifactorial systemic disease. Ther Adv Respir Dis. 2011;5:217-224.

4. Jenkins C, Rodriguez-Roisin R. Quality of life, stage severity and COPD. Eur Respir J. 2009;33:953-955.

5. Bakas T, McMlennon S, Carpenter J, et al. Systematic review of health-related quality of life outcomes. Health Qual Life Outcomes. 2012;10:134.

6. Moriarty D, Zack M, Kobau R. The Centers for Disease Control and Prevention's Health Days Measures - population tracking of percieved physical and mental health over time. Health Qual Life Outcomes. 2003;1:37.

7. Curtis J, Patrick D. The assessment of health status among patients with COPD. Eur Respir J. 2003;21:36s-45s.

8. Jones P, Brusselle G, Dal Negro R, et al. Health-related quality of life in patients by COPD severity within primary care in Europe. Respir Med. 2011;105:57-66. 
9. Weatherall M, Marsh S, Shirtcliffe P, Williams M, Travers J, Beasly R. Quality of life measured by the St George's Respiratory Questionnaire and spirometry. Eur Respir J. 2009;33:1025-1030.

10. Monteagudo M, Rodriguez-Blanco T, Llagostera M, et al. Factors associated with changes in quality of life of COPD patients: a prospective study in primary care. Respir Med. 2013;107:1589-1597.

11. Garrido PC, de Miguel Diez J, Gutierrez JR, et al. Negative impact of chronic obstructive pulmonary disease on the health-related quality of life of patients. Results of the EPIDEPOC study. Health Qual Life Outcomes. 2006;4:31.

12. Donaldson GC, Wilkinson TMA, Hurst JR, Perera WR, Wedzicha JA. Exacerbations and time spent outdoors in chronic obstructive pulmonary disease. Am J Respir Crit Care Med. 2005;171:446-451.

13. Almagro P, Barreiro B, Ochoa de Echaguen A, et al. Risk factors for hospital readmissions in patients with chronic obstructive pulmonary disease. Respiration. 2006;73:311-317.

14. Gudmundsson G, Gislason T, Janson C, et al. Risk factors for rehospitalistion in COPD: role of health status, anxiety and depression. Eur Respir J. 2005;26:414-419.

15. Osman I, Godden D, Friend J, Legge J, Douglas J. Quality of life and hospital re-admission in patients with chronic obstructive pulmonary disease. Thorax. 1997;52:67-71.

16. Almagro P, Calbo E, Ochoa de Echaguen A, et al. Mortality after admission for COPD. Chest. 2002;121:1441-1448.

17. Domingo-Salvany A, Lamarca R, Ferrer M, et al. Health-related quality of life and mortality in male patients with chronic obstructive pulmonary disease. Am J Respir Crit Care Med. 2002;166:680-685.

18. Crockett A, Cranston J, Moss J, Alpers J. The impact of anxiety, depression and living alone in chronic obstructive pulmonary disease. Qual Life Res. 2002;11:309-316.

19. Al-shair K, Dockry R, Mallia-Milanes B, Kolsom U, Singh D, Vetsbo J. Depression and its relationship with poor exercise capacity, BODE index and muscle wasting in COPD. Respir Med. 2009;103:1572-1579.

20. Martinez Frances M, Tordera M, Fuster A, Martinez Moragon E, Torrero L. [Impact of baseline and induced dyspnea on the quality of life of patients with COPD]. Arch Bronconeumol. 2008;44:127-134. Spanish.

21. Quint J, Baghai-Ravary R, Donaldson G, Wedzicha J. Relationship between depression and exacerbations in COPD. Eur Respir Rev. 2008;32:53-60.

22. Di Marco F, Verga M, Reggente M, et al. Anxiety and depression in COPD patients: the roles of gender and disease severity. Respir Med. 2006;100:1767-1774.

23. Peruzza S, Sergi G, Vianello A, et al. Chronic obstructive pulmonary disease (COPD) in elderly subjects: impact on functional status and quality of life. Respir Med. 2003;97:612-617.

24. Balcells E, Gea J, Ferrer J, et al. Factors affecting the relationship between psychological status and quality of life in COPD patients Health Qual Life Outcomes. 2010;8:108.

25. Tsiligianni I, Kocks J, Tzanakis N, Siafakas N, van der Molen T Factors that influence disease-specific quality of life or health status in patients with COPD: a systematic review and meta-analysis or Pearson correlations. Prim Care Respir J. 2011;20:257-268.

26. Iguchi A, Senjyu H, Hayashi Y, et al. Realtionship between depression in patients with COPD and the percent of predicted FEV1, BODE index, and health-related quality of life. Respir Care. 2013;58:334-339.

27. Boros P, Lubinski W. Health state and quality of life in patients with chronic obstructive pulmonary disease (COPD) in Poland: a study using the EuroQoL-5D questionnaire. Pol Arch Med Wewn. 2012;122:73-81.

28. Stewart A, Hays R, Ware J. The MOS Short Form General Health Survey. Med Care. 1988;26:724-735.

29. Kim H, Kunik M, Molinari V, et al. Functional impairment in COPD patients: the impact of anxiety and depression. Psychosomatics. 2000;41:465-471.

30. Felker B, Katon W, Hedrick S, et al. The association between depressive symptoms and health status in patients with chronic pulmonary disease. Gen Hosp Psychiatry. 2001;23:56-61.
31. Moher D, Liberati A, Tetzlaff J, Altman D. Preferred reporting items for systematic reviews and meta-analysis: the PRISMA statement. $B M J$. 2009;339:b2535.

32. Global Initiative for Chronic Obstructive Lung Disease. Global Strategy for the Diagnosis, Management, and Prevention of Chronic Obstructive Pulmonary Disease. 2010. Available from: http://www.goldcopd. org/uploads/users/files/GOLDReport_April112011.pdf. Accessed March 11, 2014.

33. Centre for Reviews and Dissemination University of York. Systematic Reviews. CRD's guidance for undertaking reviews in health care, 2009. Available from: http://www.york.ac.uk/inst/crd/pdf/ Systematic_Reviews.pdf. Accessed March 11, 2014.

34. Thomos B, Ciliska D, Dobbins M, Micucci S. A process for systematically reviewing the literature: providing the research evidence for public health nursing interventions. Worldviews Evid Based Nurs. 2004;1:176-184.

35. Jones PW, Quirk FH, Baveystock CM. The St George's Respiratory Questionnaire. Respir Med. 1991;85:25-31

36. Hedges L, Olkin I. Statistical Methods for Meta-Analysis. Orlando, FL, USA: Academic Press; 1985.

37. Borenstein M, Hedges L, Higgins J, Rothstein H. Introduction to Meta-Analysis. 1st ed. New York, NY, USA: Wiley; 2009.

38. Lipsey M, Wilson D. Practical Meta-Analysis. London, UK: Sage Publications; 2001.

39. Oga T, Nishimura K, Tsukino M, Sato S, Hajiro T, Mishima M. Longitudinal deteriorations in patient reported outcomes in patients with COPD. Respir Med. 2007;101:146-153.

40. Coventry P, Gemmell I, Todd C. Psychosocial risk factors for hospital readmission in COPD patients on early discharge services: a cohort study. BMC Pulm Med. 2011;11:49.

41. Higgins J, Thompson S, Deeks J, Altman D. Measuring inconsistency in meta-analysis. BMJ. 2003;327:557-560.

42. Ng T, Niti M, Tan W, Cao Z, Ong K, Eng P. Depressive symptoms and chronic obstructive pulmonary disease. Arch Intern Med. 2007;167:60-67.

43. Andenaes R, Moum T, Kalfoss M, Wahl A. Changes in health status, psychological distress, and quality of life in COPD patients after hospitalisation. Qual Life Res. 2006;15:249-257.

44. Engstrom C, Persson L, Larsson S, Sullivan M. Health related quality of life in COPD: why both disease-specific and generic measures should be used. Eur Respir J. 2001;18:69-76.

45. Graydon J, Ross E, Webster P, Goldstein R, Avendano M. Predictors of functioning of patients with chronic obstructive pulmonary disease. Heart Lung. 1995;24:369-375.

46. Guyatt GH, Berman LB, Townsend M, Pugslet SO, Chamber LW. A measure of quality of life for clinical trials in chronic lung disease. Thorax. 1987;42:773-778.

47. Gilson B, Gilson J, Bergner M, et al. The sickness impact profile. Development of an outcome measure of health care. Am J Public Health 1975;65:1304-1310.

48. Zigmond A, Snaith R. The Hospital Anxiety and Depression Scale. Acta Psychiatr Scand. 1983;67:361-370.

49. Derogatis LR, Lipman RS, Rickels K, Uhlenhuth EH, Covi L. The Hopkins Symptom Checklist (HSCL): a self-report symptom inventory. Behav Sci. 1974;19:1-15.

50. McNair DM, Lorr M, Droppleman LF. Profile of Mood States. San Diego, CA, USA: Educational and Industrial Testing Service; 1981.

51. Patel M, Doku V, Tennakoon L. Challenges in recruitment of research participants. Adv Psychiatr Treat. 2003;9:229-238.

52. Kontopantelis E, Springate D, Reeves D. A re-analysis of the Cochrane Library data: the dangers of unobserved heterogeneity in meta-analysis. PLoS One. 2013;8(7):e69930.

53. Dickersin K. Publication bias: recognizing the problem, understanding its origins and scope, and preventing harm. In: Rothstein H, Sutton A, Borenstein M, editors. Publication Bias in Meta-Analysis: Prevention, Assessment and Adjustments. New York, NY, USA: Wiley; 2005.

54. Egger M, Davey-Smith G, Schneider M, Minder C. Bias in meta-anlaysis detected by a simple, graphical test. BMJ. 1997;315:629-634. 
55. Kontopantelis E, Reeves D. Performance of statistical methods for meta-analysis when true study effects are non-normally distributed: a simulation study. Stat Methods Med Res. 2012;21:409-426.

56. Livermore N, Sharpe L, McKenzie D. Prevention of panic attacks and panic disorder in COPD. Eur Respir J. 2010;35:557-563.

57. Willgoss T, Yohannes A. Anxiety disorders in patients with chronic obstructive pulmonary disease: a systematic review. Respir Care. 2013;58:858-866.

58. Davidoff J, Chistensen S, Khalili D, Nguyen J, Ishak W. Quality of life in panic disorder: looking beyond symptom remission. Qual Life Res. 2012;21:945-959.

59. Sherbourne C, Wells K, Judd L. Functioning and well-being of patients with panic disorder. Am J Psychiatry. 1996;153:213-218.

60. Muller-Tasch T, Frankenstein L, Holzapfel N, et al. Panic disorder in patients with chronic heart failure. J Psychosom Res. 2008;64: 299-303.

61. Ludman E, Katon W, Russon J, et al. Panic episodes among patients with diabetes. Gen Hosp Psychiatry. 2006;28:475-481.

62. Dowson C, Kuijer R, Town I, Mulder R. Impact of panic disorder upon self-management educational goals in chronic obstructive pulmonary disease. Chron Respir Dis. 2010;7:83-90.

63. Yellowlees P, Alpers J, Bowden J, Bryant G, Ruffin R. Psychiatric morbidity in patients with chronic airflow obstruction. Med J Aust. 1987;146:305-307.
64. Moore C, Zebb B. Functional status in chronic obstructive pulmonary disease: the moderating effects of panic. Int $J$ Rehabil Health. 1998;4:83-93.

65. Effing T, Monninkhof E, van der Valk P, Zeilhuis G, vn der Palen J, Zwerink M. Self-management education in chronic obstructive pulmonary disease (COPD). Cochrane Database Syst Rev. 2007;4: CD002990.

66. McGeoch G, Willsman K, Dowson C, et al. Self-management plans in the primary care of patients with chronic obstructive pulmonary disease. Respirology. 2006;11:611-618.

67. Coventry P, Bower P, Keyworth C, et al. The effect of complex interventions on depression and anxiety in chronic obstructive pulmonary disease: systematic review and meta-analysis. PLoS One. 2013;8:e60532.

68. Katon W, Lin E, Von Korff M, et al. Collaborative care for patients with depression and chronic illness. N Engl J Med. 2010;363:2611-2620.

69. Fan V, Gaziano M, Lew R, et al. A comprehensive care management program to prevent chronic obstructive pulmonary disease hospitalizations: a randomized controlled trial. Ann Intern Med. 2012;156:673-683.

70. Boersma S, Maes S, Joekes K, Dusseldorp E. Goal processes in relation to goal attainment: prediciting health-related quality of life in myocardial infarction patients. J Health Psychol. 2006;11:927-941.
International Journal of COPD

\section{Publish your work in this journal}

The International Journal of COPD is an international, peer-reviewed journal of therapeutics and pharmacology focusing on concise rapid reporting of clinical studies and reviews in COPD. Special focus is given to the pathophysiological processes underlying the disease, intervention programs, patient focused education, and self management protocols.

\section{Dovepress}

This journal is indexed on PubMed Central, MedLine and CAS. The manuscript management system is completely online and includes a very quick and fair peer-review system, which is all easy to use. Visit http://www.dovepress.com/testimonials.php to read real quotes from published authors. 